\title{
Analysing Lexico-grammatical Features in Chimamanda Ngozie Adichie's Americanah
}

\author{
Innocent Sourou Koutchadé ${ }^{1} \&$ Crépin Loko ${ }^{2}$ \\ ${ }^{1}$ Département d'Anglais, Université d'Abomey-Calavi, République du Bénin \\ ${ }^{2}$ Département d'Anglais, Université d'Abomey-Calavi, République du Bénin \\ Correspondence: Innocent Sourou Koutchadé, Département d'Anglais, Faculté des Lettres, Arts et Sciences \\ Humaines (FLASH), Université d' Abomey-Calavi, 01BP 526 Cotonou, République du Bénin, Tél. 229-96-518-643.
}

Received: August 15, 2016

Accepted: August 30, $2016 \quad$ Online Published: September 3, 2016

doi:10.5430/elr.v5n3p72

URL: http://dx.doi.org/10.5430/elr.v5n3p72

\begin{abstract}
This article aims at carrying out an analysis of Chimamanda Ngozi Adichie's Americanah (2013), using the Systemic Functional Linguistics (SFL). Such a linguistic approach views language as a strategic meaning-making resource (Halliday \& Matthiessen, 2004; Eggins, 1994). The main and specific goal of the present study is to describe and analyse the lexico-grammatical features, characteristics of the language of Adichie's Americanah. This leads to focus on the study of linguistic patterns such as Transitivity, Mood and Theme in three selected excerpts from the novel. The socio-cultural context of the production of the novel has made it easy to discuss and interpret the salient linguistic patterns which reveal the generic structure potential of the novel and has facilitated the study of how the novelist has woven her text as a message of alert through the depiction of such issues as immigration, love, race and identity in the context of today's globalised world.
\end{abstract}

Keywords: Systemic Functional Linguistics (SFL), Chimamanda Ngozi Adichie, Transitivity, Mood, Theme

Résumé

Cet article se propose d'analyser le roman Americanah (2013) de Chimamanda Ngozi Adichie à travers la Linguistique Systémique Fonctionnelle (LSF). Une telle théorie considère la langue comme étant une ressource stratégique de création de sens (Halliday \& Matthiessen, 2004; Eggins, 1994). L'objectif principal et spécifique de cette étude est de décrire et d'analyser les traits lexico-grammaticaux qui caractérisent la langue du roman Americanah de Adichie. Ceci permet de focaliser l'étude sur les traits linguistiques tels que la transitivité, le mode, et le thème dans trois extraits tirés du roman. Le contexte socio-culturel de production du roman a facilité la discussion et l'interprètation des traits linguistiques remarquables qui révèlent la structure générique importante du roman et a rendu possible le mécanisme par lequel l'écrivaine a tissé l'oeuvre en tant que message d'alerte, à travers sa représentation des problèmes tels que l'immigration, l'amour, la race et l'identité dans le contexte actuel de mondialisation.

Mots-Clés: Linguistique Systémique Functionnelle (LSF), Chimamanda Ngozi Adichie, Transitivité, Mode, Thème.

\section{Introduction}

Systemic Functional Linguistics considers language as a meaning-making potential that human beings have at their disposal (Halliday, 1985/1994; Halliday \& Matthiessen, 2004). Indeed, language, an important medium of communication, helps people to make statements, commands, questions, and offers in their everyday situations. In this perspective, language is obviously used to create meanings. The creation of such meanings involves choices of words within given cultural and situational contexts. Halliday (1985, pp.7-11) quoted in Wattles and Radié-Bojanié (2007) gives an account of the basic concepts of his theory by saying that "language exists and must be studied in various contexts".

The present paper uses the systemic functional theory to carry out a lexico-grammatical analysis of selected exerpts from Americanah by Adichie. The main purpose of the present analysis is to study the language of Americanah in order to unravel the linguistic features which have characterized it and to find out how language is used therein "to mean what it does" (Halliday, 1985, p. xxx) . To achieve this, three excerpts have, chronologically, been drawn from the novel, and the study of the lexico-grammatical features has, methodically, been carried out at the level of the identified clauses. A systematic understanding of these linguistic features, above- mentioned, implies the study of the 
three metafunctions in the novel in order to facilitate the understanding and interpretation of the socio-cultural context of the production of the novel, on the one hand, and of the experiential, interpersonal and textual meanings within this selected literary artefact of the writer, on the other.

\section{Theoretical Framework: Contexts and Lexico-grammatical Properties}

A specific aspect of a given context leads to a range of meanings likely to be expressed and the adequate language that will fit to convey those meanings in such a context. In addition, the choice and the use of linguistic elements such as the topic being discussed (field), the participants (tenor) and the medium of communication (mode) are influenced by the other specific aspects of the context of the communicative event. Thus, Eggins (1994) has devised two types of context which are: context of culture also referred to as genre, and context of situation also known as register.

The context of culture or genre is a general framework which gives an account of how language is used to achieve culturally appropriate goals. This is seen as a manifestation of language choices with a social purpose (Eggins 1994, p.25). It is a potential resource for the system of language. Genre is culture-dependent and that is the reason why language is shaped according to the social and personal needs that it is required to serve (Lyons, 1970, p. 142; Fowler 1996, p. 111). The meanings of the words reflect the stored knowledge of the members of the speech community; and, language, as a medium, allows the transmission of this stored knowledge among the members of that community (Berger \& Luckmann, 1976). In the similar vein, the meaning in/of a text, according to Halliday (1985) and Eggins (1994), is determined by three linguistic parameters which are: (1) context of culture, (2) context of situation, and (3) metafunctions as shown in figure 1.

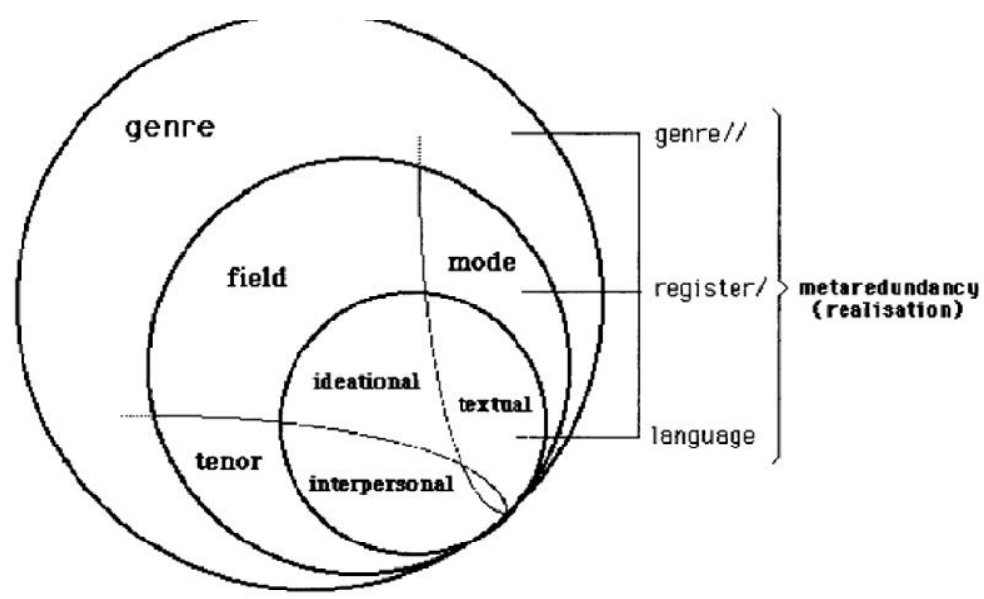

Figure 1. Genre, Register, and Language. (Martin \& Rose, 2003, p. 254)

According to Eggins (1994), the context of situation or register can be realized by three variables which are field, mode, and tenor. Field is what language is being used to talk about. As for mode, it reveals the communicative role that language is playing in the interaction. Finally, the third variable of register, i.e., tenor, points out the role relationships existing between language users or interactants. Each register variable is associated with a precise strand of meaning. While field determines experiential meaning, tenor defines interpersonal meaning, and mode defines textual meaning. Experiential meaning pertains to the construction of speech event and entities labelled as process, participant and attendant circumstances. In other words, it focuses on the writer's/ speaker's use of language to represent his/her world. As for interpersonal meaning, it has to do with the way a speaker situates him/herself in the negotiation of information or desired actions, i.e., the "Mood" (Halliday \& Matthiessen, 2004) and is, therefore, expressed through "Subject" and "Finite" or "Mood block" and "Residue". Finally, the textual meaning deals with the organization of the clauses as message and is expressed through the "Theme/Rheme" system to unravel the way in which the writer signposts his/her text so as to orient readers from one idea to the next. From the foregoing, Field determines Transitivity patterns, Mode determines Theme patterns, and Tenor determines Mood patterns (Halliday 1978, p. 64).

\section{Analytical Results}

The present section deals with the analysis of the lexico-grammatical features in the three excerpts selected for the study. The selection of these excerpts is in conformity with the chronological account of events around three main 
periods mentioned in the novel. As a matter of fact, the first extract depicts characters who have left their country Nigeria, in time of war for the United States of America. While the second excerpt deals with the life of the emigrant characters in the United States, the third one sheds light on the coming back of those emigrants to Nigeria in time of peace. In this section, we have carried out practical analyses of lexico-grammar in terms of transitivity, mood, and theme patterns, and that of register variables within the Hallidayan framework in these excerpts. In order to arrive at inclusive results, excerpt one is analysed for Transitivity patterns, excerpt two for Mood patterns and the third excerpt is analysed for Theme patterns according to keys presented below as suggested by Eggins (1994). Moreover, to be in accordance with the linguistic requirements of the SFL, the extracts have been segmented into numerically manageable clauses. Some clauses are simple and others are complex but minor clauses are left unanalysed. Thus, specific keys are used to identify the linguistic patterns to be analysed.

\subsection{Transitivity Analysis}

\subsubsection{Identifying Transitivity Elements}

Keys:

$\mathrm{P}=$ Process, $\mathrm{Pb}=$ behavioural, $\mathrm{Pc}=$ causative, $\mathrm{Pcc}=$ circumstantial, $\mathrm{Pe}=$ existential, $\mathrm{Pi}=$ intensive, $\mathrm{Pm}=\mathrm{material}$, $\mathrm{Pme}=$ mental, $\mathrm{Pp}=$ possessive $\mathrm{Pv}=$ verbal.

$\mathrm{A}=$ Actor, $\mathrm{At}=$ Attribute, $\mathrm{B}=$ Beneficiary, $\mathrm{Be}=$ Behaver, $\mathrm{Bh}=$ Behaviour, $\mathrm{C}=$ Circumstance, $\mathrm{Ca}=$ accompaniment, $\mathrm{Cc}=$ cause, $\mathrm{Cl}=$ location, $\mathrm{Co}=$ role, $\mathrm{Cr}=$ Carrier, $\mathrm{Ct}=$ matter, $\mathrm{Cx}=$ extent, $\mathrm{G}=$ Goal, $\mathrm{R}=$ Range, $\mathrm{S}=$ Senser, $\mathrm{Pd}=$ possessed, $\mathrm{Ph}=$ Phenomenon, $\mathrm{Pr}=$ possessor, $\mathrm{Rv}=$ Receiver, $\mathrm{Sy}=$ Sayer, $\mathrm{T}=$ Token, $\mathrm{V}=$ Value, $\mathrm{Vb}=$ Verbiage, $\mathrm{X}=$ Existent.

Excerpt 1: (Americanah, p.3)

Princeton, $(\mathrm{Be})$ in the summer, $(\mathrm{Cl})$ smelled $(\mathbf{P b})$ of nothing, $(\mathrm{Ph}) /(2)$ and although Ifemelu (S) liked (Pme) the tranquil greenness of the many trees, $(\mathrm{Ph})$ [the clean streets and stately homes, $(\mathrm{Ph})$ the delicately overpriced shops and the quiet, abiding air of earned grace, $(\mathrm{Ph})] /(3) \operatorname{it}(\mathrm{T})$ was $(\mathbf{P i})$ this, the lack of a smell, (V)/ (4) that $(\mathrm{Ph})$ most appealed (Pme) to her, (S) / (5) perhaps because the other American cities (Be) [she (S) knew (Pme) well] had all smelled (Pb) distinctly. $(\mathrm{Cm}) /(6)$ Philadelphia (Pr) had (Pp) the musty scent of history. (Pd)/ (7) New Haven (Be) smelled (Pb) of neglect (Bh)./ (8) Baltimore (Be) smelled (Pb) of brine, (Bh) and Brooklyn (Be) of sun-warmed garbage. (Bh) / (9) But Princeton (Pr) had (Pp) no smell. (Pd) / (10) She (S) likes taking (Pme) deep breaths (Ph) her./ (11) She (S) likes watching (Pme) the locals (Ph) / (12) who (A) drove (Pm) with pointed courtesy (R)/ (13) and parked (Pm) their latest-model cars $(\mathrm{G})$ outside the organic grocery store on Nassau Street $(\mathrm{Cl})$ [or outside the sushi restaurants or outside the ice cream shop] / (14) that (Pr) had (Pp) fifty different flavours including red pepper (Pd) or outside the post office $(\mathrm{Cl}) /(15)$ where $(\mathrm{Cl})$ effusive staff $(\mathrm{A})$ bounded out $(\mathrm{Pm})$ to greet them $(\mathrm{G})$ at the entrance.(Cl) / (16) She (S) liked (Pme) the campus $(\mathrm{Ph})$, grave with knowledge, the Gothic buildings with their vine-laced walls, / (17) and the way (Cx) everything (A) transformed, (Pm) in the half-light of night, (Cm) into a ghostly scene. (G)/ (18) She (S) likes, (Pme) most of all, $(\mathrm{Ph})$ that in this place of affluent ease, $(\mathrm{Ph}) /(19)$ she $(\mathrm{S})$ could pretend to be (Pme) someone else, $(\mathrm{Ph}) /(20)$ someone (B) specially admitted(Pm) into a hallowed American club, (Cl) / (21) someone (B) adorned (Pm) with certainty (Cm). (22) But she (S) did not like (Pme) / (23) that she (A) had to go (Pm) to Trenton to braid her hair. (G) / (24) It (Cr) was (Pi) unreasonable (At) to expect(Pme) a braiding salon in Princeton (X) - / (25) the few black locals (Cr) she (S) had seen (Pme)were (Pi) so light (At)- skinned and lank-haired (Cx) / (26) she (S) could not imagine (Pme) them (Ph)/ wearing (Pm) braids $(\mathrm{G})]-/(27)$ and $(\mathrm{Cx})$ yet as she (A) waited (Pm) at Princeton Junction station (Cl) for the train, $(\mathrm{Cc})$ on an afternoon ablaze with heat, $(\mathrm{Cl}) /(28)$ she $(\mathrm{S})$ wondered (Pme) / (29) why $(\mathrm{Cc})$ there $(\mathrm{Cr})$ was (Pi) no place (At) / (30) where (Cl) she (A) could braid (Pm) her hair. (G)/ (31) The chocolate bar (A) in her handbag (Cl) had melted (Pm).

\subsubsection{Analysis of Transitivity Patterns In Excerpt 1}

The analysis of the different Transitivity patterns helps to uncover the various process types embedded in the text of Americanah and the way the clauses are organized as representation of experience. The process types' rates and percentages can be summarized in the following table. 
Table 1. Statistics of Process-types in excerpt 1

\begin{tabular}{llll}
\hline & Process types & \multicolumn{2}{c}{ Excerpt 1} \\
\cline { 3 - 4 } & & Number & Percentage \\
\hline Material process & 11 & $32 \%$ \\
Mental process & 13 & $37 \%$ \\
Behavioural process & 4 & $11 \%$ \\
Verbal process & & 0 & $00 \%$ \\
Existential process & & 0 & $00 \%$ \\
& Attribute process & 0 & $00 \%$ \\
Relational & Identifying process & 0 & $00 \%$ \\
processes & Intensive process & 4 & $11 \%$ \\
& Possessive process & 3 & $9 \%$ \\
Total & & 35 & $100 \%$ \\
\hline
\end{tabular}

The present table indicates that mental processes rank first, i.e., (37\%) in the excerpt. Material processes come second, i.e., (32\%) after the mental ones. Behavioural processes and intensive processes rank third, i.e., (11\%) while possessive processes rank fourth, i.e., (9\%). Verbal, attribute, existential and identifying processes are non-existent in the excerpt.

The predominance of mental processes, i.e., 37\% proves that the author generally reveals the inner side of some young African generation that are the fictitious characters in the novel. The 13 mental processes can be classified into three categories of clauses as follows: clauses denoting perception (seeing, hearing...), clauses denoting cognition (thinking, knowing, understanding...) and clauses denoting affection (liking, fearing). These mental processes can be found in $(2,4,5,10,11,16,18,19,22,24,25,26$, and 28). They involve two participants, i.e., the senser and the phenomenon. The senser role is only played by Ifemelu, anaphorically referred to as "she" in the excerpt, and the phenomena are either abstract nouns (the smell, the depth breaths...) or tangible objects (tranquil greenness of many trees, American cities, the locals, the campus).

The presence of $32 \%$ material processes indicates that the excerpt is also about actions and events. The material processes identified in $(12,13,15,17,20,21,23,26,27,30,31)$ involve, at least, one or two participants which are referred to as actor and goal/range/beneficiary doing or undergoing something. Actor roles are played by Ifemelu, Philadelphia, the locals, and the chocolate bar. There are 4 behavioural processes, i.e., $11 \%$ of all process types in the excerpt. Behavioural processes are identified in $(1,5,7$, and 8$)$. In these clauses, the behaver role is played by the town, and the narrator refers to, respectively, as Princeton, other American cities, New Haven, and Baltimore.

In addition, there are 5 relational processes in the extract. The clause-by-clause transitivity analysis encompasses intensive and possessive processes only. The above table shows 4 instances of intensive processes, i.e., $11 \%, 3$ possessive processes, i.e., $9 \%, 0$ attribute processes, i.e., $0 \%$, and 0 identifying processes, i.e., $0 \%$ of the 35 processes identified in the whole excerpt. These statistics indicate an actual presence of intensive and possessive processes whereas attribute and identifying processes are non-existent. Intensive processes are identified in (3, 24, 25, 29 ), and possessive processes are identified in $(6,9,14)$. The carrier role is played by "it" in $(4,24)$, "the few black locals" in 25 and entities referred to as "there" in (29). In the case of possessive processes, the possessors are American towns and restaurants such as "Philadelphia", "Princeton" and "sushi restaurants or the ice cream shop" in $(6,9,14)$, respectively. The absence of verbal processes in the excerpt suggests that the extract has less to do with exchange or interaction between characters. This may also be justified by the fact that the story, in this extract, has been told by a narrator outside the text; she understands situations, circumstances, and people's behavior, and gives a detailed account of them.

Finally, as can be noticed in the previous sub-section, the study has also uncovered four main categories of circumstantial elements which are that of location, manner, extent and cause. The predominant proportion of circumstances of location means that the writer has situated events in time and space by pinpointing where these events take place. Then, the presence of circumstances of manner reveals that the text is concerned with the way events happen. In addition, the presence of circumstances of extent shows the reader how these events occur in time and place, and the use of circumstances of cause indicates that the text has merely exemplified features of what has 
caused the absence of hair braiding salon in Princeton.

\subsection{Mood Analysis of Excerpt 2}

\subsubsection{Identification Mood Elements in Excerpt 2}

Keys:

$\mathrm{A}=$ Adjunct, $\mathrm{Ac}=$ circumstantial, $\mathrm{Aj}=$ conjunctive $, \mathrm{Am}=\mathrm{Mood}, \mathrm{Ao}=$ comment, $\mathrm{Ap}=$ polarity, $\mathrm{At}=$ continuity, $\mathrm{Av}=\mathrm{vocative}$, $\mathrm{C}=$ Complement, $\mathrm{Ca}=$ attributive Complement, $\mathrm{F}=$ Finite, $\mathrm{Fn}=$ negative, $\mathrm{Fml}=$ modulated, $\mathrm{Fms}=$ modalised, $\mathrm{F} / \mathrm{P}=$ fused Finite and Predicator, $\mathrm{mn}=$ minor clause, $\mathrm{P}=$ Predicator, $\mathrm{Pms}=$ modalised Predicator, $\mathrm{Pml}=$ modulated predicator, $\mathrm{S}=$ Subject, $\mathrm{Wh}=\mathrm{Wh}$ element, $\mathrm{Wh} / \mathrm{S}, \mathrm{Wh} / \mathrm{C}, \mathrm{WhAc}=$ fused $\mathrm{Wh}$ element, Mood element is in bold

Exerpt 2 ( Americanah, p.115)

(1) Aunty Uju (S) came (F/P) home dry-faced and tense (C), [the streets dark and Dike already in bed,] to ask /(2) "do (F) I (S) have (P) mail(C)? /(3) Do (F) I(S) have (P) mail(C)?" /(4) the question (S)always (Ac) repeated (F/P) her entire being at a perilous edge, about to tip over(C). /(5) Some nights, (Ac) she (S) would (Fms) talk (P) on the phone for a long time, her voice hushed(C), $/(6)$ as though $($ Ao) she $(\mathbf{S})$ were(F) protecting $(\mathrm{P})$ something from the world's prying gaze (C). /(7) Finally, (Ac) she (S) told (F/P) Ifemelu (C) about Bartholomew(Ca). /(8) "He (S) is (F) an accountant, divorced(Ca), /(9) and (Aj) he (S) is (F) looking $(\mathrm{P})$ to settle down $(\mathrm{C})$. /(10) He (S) is (F) from Eziowelle, very near us.(Ac)" (11) Ifemelu (Av), floored (Am) by Aunty Uju's words (Ca), could(F) only say (P), "Oh. Okay (At) and (Aj) nothing else (C)./(12) "What(Wh/C) does (F) he (S) do (P)?" /(13) and(Aj) "Where $(\mathrm{Wh} / \mathrm{C})$ is $(\mathbf{F})$ he(S) from $(\mathrm{C})$ ?" / (14) were $(\mathrm{F})$ the questions $(\mathrm{C})$ her own $\quad$ (S)would (Fms) ask (P), /(15) but(Aj) when (Ac) had (F) it (S) started (P) to matter to Aunty $\mathrm{Uju}(\mathrm{C}) /(16)$ that (Aj) a man (S) was (F) from a hometown close to theirs (Ca)? (17) One Saturday,(Ac) Bartholomew (S)visited(F/P) from Massachusetts (Ca)./(18) Aunty Uju (S) cooked(F/P) peppered gizzards, (C) powdered (F/P) her face// and (Aj) stood (F/P) by the living room window (Ac), waiting to see his car pull in (C)./(19) Dike (S) watched (F/P) her, (C) playing half-heartedly with his action figures, (Ao) confused(F/P) // but (Aj) also (At) excited (F/P) /(20) because (Aj) he (S) could (Fml) sense (P) her expectation (C). /(21) When (Aj) the doorbell (S) rang, (F/P)/ (22) she (S) told (F/P) Dike (C) urgently, (Ac) /(23) "Behave (P) well (C)!” (24) Bartholomew (S)wore (F/P) khaki trousers (C) pulled up high on his belly, (Ca)// and (Aj) spoke (F/P) with an American accent filled with holes, (Ac) mangling words/(25) until (At) they (S) were (F) impossible to understand.(C) /(26) Ifemelu (S) sensed, (F/P) from his demeanour, (Ac) a deprived rural up bringing/(27) that $(\mathrm{Aj})$ he $(\mathbf{S}) \operatorname{tried}(\mathbf{F} / \mathbf{P})$ to compensate for with his American affection, (C) his gonnas and wannas. (Ao)

(28) He (S) glanced (F/P) at Dike, (C) // and (Aj) said (F/P), almost indifferently, (Ac) "Oh, (At) yes, (At) your boy. (C) / (29) How (Wh/C) are (F) you (S) doing (P)?" /(30) "Good," (At) Dike (S) mumbled. (F/P) /(31) It (S) irked (F/P) Ifemelu (C) /(32) that (Aj) Bartholomew (S) was not (Fn) interested in (P) the son of the woman (C)

\subsubsection{Mood Patterns Analysis}

The present analysis is meant to investigate the system of mood embedded in the second excerpt and the way the clauses are organized as exchange so as to find out the social relationship language plays between the characters or the participants in this selected text. The table below displays the statistics of the mood- types in the excerpt.

Table 2. Statistics of mood-types in excerpt 1

\begin{tabular}{lll}
\hline Mood types & \multicolumn{2}{l}{ Excerpt 2} \\
\cline { 2 - 3 } & Number & Percentage \\
\hline Declarative & 25 & $78 \%$ \\
Interrogative & 6 & $18.8 \%$ \\
Imperative & 1 & $3.2 \%$ \\
Total & 32 & $100 \%$
\end{tabular}

From the above table, it can be noticed that declarative mood clauses are the most predominant with a figure of (78\%). Interrogatives rank second (18.8\%) while imperative mood clauses rank third (3.2\%) in the excerpt. The high rate $(78 \%)$ of declarative mood clauses in the excerpt means that the text is made to inform readers about the daily life of the characters. In actual fact, it can be noted that the conversation, in the extract, is mainly held by Aunty Uju 
(anaphorically referred to as "she" and "I"), Ifemelu, Bartholomew (anaphorically referred to as "he"), and Dike (also, anaphorically referred to as "he") in (1, 4, 5, 6, 7, 8, 9, 10, 11, 14, 16, 17, 18, 19, 20, 21, 22, 24, 25, 26, 27, $28,30,31$, and 32 ). In these mentioned clauses, the subject role is mostly played by conscious beings, i.e., Aunty Uju, Ifemelu, Bartholomew and Dike who are giving information related to each other's attitudes or wishes and their daily routines in a host country.

The 6 interrogative mood clauses in the excerpt include polar interrogatives $(2,3)$ and wh-interrogatives $(12,13,15$, and 29) and represent $18.8 \%$ of the overall mood- types. Polar interrogatives used in $(2,3)$ are put by Aunty Uju as she comes very late in the night to know whether people have sent her e-mails either through her personal friends, about the on-going situations in Nigeria or about the result of an application she has sent to the physician family of America. This repetition implies that a particular attention is paid to her e-mails. In fact, Ifemelu, a blogger, and Aunty Uju, a medical doctor, who are waiting for recruitment, are always connected to the internet in order, for Ifemelu, to write articles on her blogs on time and, for Aunty Uju, not to be out of step by the results of recruitment she is waiting for. The Wh-interrogatives which have been used in $(12,13,15$,) have been put by Ifemelu and that in 29 by Bartholomew. Actually, Ifemelu wants to know the origin, the profession and the matrimonial status of the man who is about to visit Aunty Uju. Answers to these questions have been provided by Aunty Uju herself because she is informed by Ifemelu that Bartholomew is an accountant, a divorced man who is looking forward to settling down.

Moreover, the text displays only one case of imperative mood. The sole case is found in (23). This very low rate of imperative (i.e., 3.2\%) suggests that the text has less to do with commands or authoritarian tenor. Likewise, the analysis reveals that there are 33 adjuncts in the excerpt. They can be ranged into five categories which are: circumstantial (10/33), mood (2/33), comment (2/33), conjunctive (13/33) and continuity (6/33). The high proportion of conjunctive adjuncts (13/33) is an indication that textual meaning is added to the mood patterns of the language of the selected excerpt, and it also points out how the narrators have produced cohesive and coherent conversation in Americanah. Circumstantial adjuncts (10/33) play an important role in that they add experiential meaning to the text and show how interactants have specified the different circumstances and settings in which events take place. The considerable presence of continuity adjuncts $(6 / 33)$ can also be added to the conjunctive ones to enhance cohesion in the excerpt. Mood and comment adjuncts are almost non-existent, i.e., (2/33 for each) in the excerpt.

\subsection{Identification and Analysis of Theme Pattern in Excerpt 3}

\subsubsection{Identification of Theme Patterns in Excerpt 3.}

Keys:

Theme: Theme is underlined, textual Theme: in italics, interpersonal Theme: in CAPITALS,

Topical Theme: in bold, dependent clause as Theme: whole clause in bold

Excerpt 3 ( Americanah, pp.473-474)

(1) One Day Ifemelu saw the male peacock dance, /(2) its feathers fanned out in a giant halo. /(3) The female stood by pecking at something on the ground/(4) and then, after a while, it walked away, indifferent to the male's great flare of feathers. /(5) The male seemed suddenly to totter,// PERHAPS from the weight of its feathers or from the weight of rejection. /(6) Ifemelu took a picture of her blog. /(7) She wondered /(8) what Obinze would think of it; $/(9)$ she remembered /(10) how he had ask/(11) ifshe had ever seen the male dance. (12) Memories of him so easily invaded her mind; /(13) she would, [in the middle of a meeting at an advertising agency,] remember Obinze pulling out an ingrown hair on her chain with tweeters, her face up on a pillow, and him very close and very keen in examination. (14) Each memory stunned her with blinding luminosity. /(15) Each brought with it a sense of

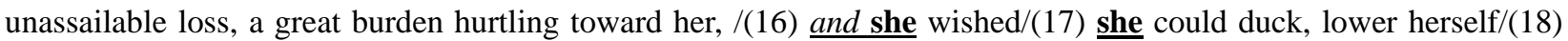
sothat it would bypass her, /(19) so that she would save herself. /(20) Love was a kind of grief. /(21) This was/(22) what the novelists meant by suffering for love, /(23) but now she understood. /(24) She carefully avoided the street in Victoria Island/(25) where his club was, /(26) and she no longer shopped at the Psalms /(27) and she imagined

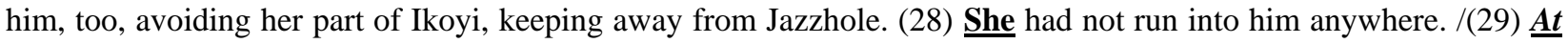
first she played "YoriYori" and "Obi Mu O" endlessly/(30) and then she stopped, /(31) because the songs brought to her memories a finality, /(32) as thoughthey were dirges. /(33) She was wounded by the half-heartedness in his

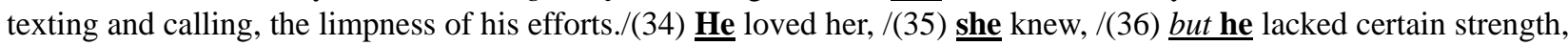
/(37) his back bone was softened by duty./(38) When she put up the post, written after a visit to Ranyinudo's office, about the government's demolishing of hawkers' shacks, an anonymous commenter wrote. /(39) This is like poetry.

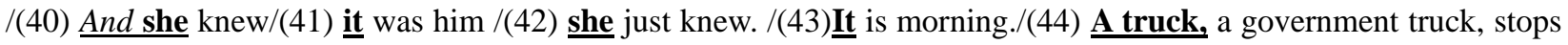
near the tall office building, [beside the hawkers' shacks, and men spill out, men hitting and destroying and leveling 
and trampling]. /(45) They destroy shacks, reduce them to flat pieces of wood. /(46) They are doing their job, wearing "demolish" like crisp business suits. /(4They themselves eat in shacks like these/(48) and if all the shacks like these disappeared in Lagos, /(49) they will go lunch less, unable to afford anything else. /(50) But they are smashing, trampling hitting. /(51) One of them slaps a woman, /(52) because she does not grab her pot and her

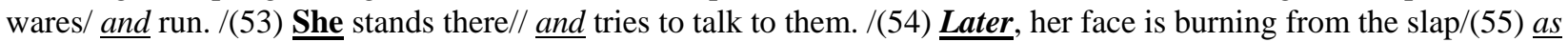
she watches her biscuits buried in dust. /(56) Her eyes trace a line towards the bleak sky. /(57) She does not know yet/(58) what she will do/(59) but shewill do something, /(60) she will regroup// and recoup// and go somewhere else// and sell her beans and rice and spaghetti cooked to a near mush, her coke and sweets and biscuits.

\subsubsection{Analysis of Theme Patterns in Excerpt 3}

The analysis of textual meaning helps to revisit the different Theme patterns in the excerpt and the way the clauses are internally organized as a message. Such an analysis involves the system of Theme and Rheme and has mainly to do with the rhetorical structure of the text. The Theme types' rates and percentages can be summarized in the following table

Table 3. Statistics of Theme-types in excerpt 3

$\begin{array}{llll}\hline \text { Theme types } & \multicolumn{2}{l}{\text { Excerpt 3 }} \\$\cline { 3 - 4 } & & \text {$\left.Number } & \text { Percentage } \\ \hline \text { Textual } & \mathbf{2 9} & \mathbf{3 2 . 2 \%} \\ \text { Interpersonal } & & \mathbf{1 \%} \\ \text { Topical } & \text { U1 } & \\ & \text { Unmarked } & \mathbf{3 6} & 60 \% \\ & \begin{array}{l}\text { Marked } \\ \text { Marked } \\ \text { dependent clause }\end{array} & \mathbf{2 4} & 40 \% \\ \text { Total } & \mathbf{0} & 0 \% \\ & & \mathbf{9 0} & \mathbf{1 0 0 \%}\end{array}\right]$

This table shows that topical Themes are predominant (66.7\%), textual Themes are significant $(32.2 \%)$ and interpersonal Themes are very low $(1 \%)$ in the third excerpt of the present study. In fact, the predominance of topical Themes, i.e., $66.7 \%$, is an indication that elements to which one can assign transitivity patterns are put in the first position of the clauses, and that the narrator has given account of real issues or topic of the extract. In other words, the very high occurrence of topical Themes suggests that experiences (actions and facts) have been shared by characters in the excerpt. In this sense, it can be insinuated that within each clause, there is an element which plays a transitivity role or function. Thus, these topical Themes are elements of the clauses that have transitivity function of actor, senser and behaver in the above identified clauses (Eggins, 2004). Such roles are mostly played by the peacocks, Ifemelu (anaphorically referred to as "she"), and Obinze (anaphorically referred to as "he").

The occurrence of $32.2 \%$ of textual Themes suggest that elements performing cohesive work, in relating the clauses to their situational context, are significantly present in the excerpt, (Eggins, 1994, p. 281). Textual elements uncovered in the text belong to the category of conjunctive adjuncts as in $(4,9,14,16,17,20,21,23,24,25,28,29$, 30 , and 35). They are either coordinators, subordinators or some other elements which connect meanings in the clauses. In other words, these are lexical elements which express linguistic relationships with what has been said before.

As for the interpersonal Theme, it only covers a proportion of $1 \%$ and indicates that the text is less concerned with authoritarian tenor or command. This is realized in (5) through comment adjuncts "Perhaps". The last category of Theme identified in excerpt 3 is topical Theme which is either marked or unmarked. According to Halliday (1985) and Eggins (1994, 2004), a topical Theme is marked when it is something other than the Subject in a declarative clause and unmarked when it conflates with the Subject in a declarative, Finite in an interrogative (yes/no question), Wh-element in a Wh-interrogative and the Predicator in an imperative Mood. Actually, 36/60 Themes are unmarked while 24/60 are marked. The predominance of unmarked Themes reveals that the writer has used language to depict issues that are current in today's globalised world. These issues are related to tender stories of enduring love, race, 
racism, and identity set over three continents that have been abundantly mentioned in the novel. Examples of unmarked Themes can be found in $(2,3,5,6,7,8,9,10,12,13,14,15,17,20,21,24,28,33,34,35,37,39,41,42$, $43,44,45,46,47,49,51,53,56,57,58$, and 60 ). The presence of the 24 marked topical Themes out of 60 indicates that the author, through the deeds and the actions of her characters, has depicted atypical issues related to the enduring love of somebody (Obinze) who is presently far away from Ifemelu in Princeton, in America. Illustrations of marked Themes are identified in $(1,4,11,16,18,19,22,23,25,26,27,29,30,31,32,36,38,40,48$, 50, 52, 54, 55, and 59). Moreover, some of the identified marked Themes can be considered as highly marked Themes. These are constituents functioning as Subject in the clause and which are not part of the Theme. Theme, in these clauses, conflates thus with Circumstantial Adjuncts in the clauses (Eggins, 1994, p. 298). Examples can be identified in (1,29 and 54).

Finally, it is important to turn to the analysis of register variables so as to be in accordance with the priorities that such a linguistic study requires. The register variables studied are field, tenor and mode. The field of excerpt 1 accounts for the very first days of the new African immigrants in the US, particularly Ifemelu, the girl friend of Obinze in Nigeria, as she has escaped from Nigeria. While that of excerpt 2 is about the schedule of the characters -Aunty Uju, Ifemelu Bartholomew and Dike -their behaviour, attitudes or wishes as well as their daily routines in a host country. Finally, excerpt 3 reveals the power of love in the novel through characters, mainly Ifemelu and Obinze, who have been separated by the war, and, when she, i.e., Ifemelu, is back home, she can still remember him, i.e., Obinze, but in a sense of undeniable loss. The author has succeeded in revealing the field by conveying the experiential meanings of process- types, participants and attendant circumstances. Such a conveyance of expression becomes possible via the use of a suitable syntax related to fictional work.

The tenor of excerpts 1 and 3 is relatively formal and there is no contact between participants as the story is narrated through the eyes of an omniscient narrator about only one character, i.e., Ifemelu in her early days in the US in excerpt 1, and in Nigeria when she is back home, years later in excerpt 3. But, there is a possible affective involvement from the readers' side because they can share the same feelings with the character. As for excerpt 2, the tenor is informal, and characters -Aunty Uju, Ifemelu, and Bartholomew -can frequently see themselves as equal in power, except for Dike, Aunty Uju's boy. Those sharing equal power in the communicative process can mostly give and demand information, and use vocatives to address one another, thus showing affective involvement between them.

The third register variable studied in the present paper is mode. It deals with the organization of the text, i.e., the medium and the channel of communication. Investigating these two issues in the selected excerpts from the novel under study, one can realize that these excerpts, in their form, are spoken texts which are however realized through written channels. The level of formality is highly due to the written channel but the aspect of spoken language, which occurs in parts, sometimes decreases the level of formality. Finally, all the excerpts selected from the novel can be considered as written texts - to - be -read.

\section{Discussion and Interpretation of the Findings}

This section is about the discussion and interpretation of the findings derived from the various analyses carried out so far. It deals with the discussion of the salient linguistic (lexico-grammatical) features that have enabled the language of Americanah to be woven as a message or a meaningful text and tackles the interpretation of the findings by taking into account the socio-cultural context of the production of the novel.

The salient linguistic features uncovered in the analyses carried out in the third section are related to the systems of Transitivity, Mood and Theme in the selected excerpts from the novel. These features identified and analysed, according to the Hallidayan theory above mentioned, in the three excerpts, have helped us to provide a new and a thorough understanding of the language of Americanah. Such an understanding encompasses the deep message, the socio-political context of the production of the novel and the personal experiences of the author regarding the multiple facets of racism, enduring love and cultural identity.

The study of transitivity patterns in the first excerpt reveals that language has been used to primarily indicate the field of discourse, i.e. what the text is about (Halliday et al. 1964, pp. 90-92) cited in Watttles and Radié-Bojanié (2007, p. 50). It has been achieved by conveying experiential meanings of processes, participants and attendant circumstances. One can, then, notice the predominance of mental processes which project the participants' beliefs and opinions. These mental processes are classified into categories of perception (seeing, hearing...), cognition (thinking, knowing, understanding...) and affection (liking, fearing), and involve two participants, i.e., the senser and the phenomenon. As said earlier, the remarkable presence of material processes indicates that the excerpt is about repeated actions of going out, driving and parking cars, greeting people and even wearing or braiding hair. The 
relatively low rate of behavioural processes in the excerpt suggests that few things have been experienced by personified cities in the excerpt since the behaver role is played by the cities the narrator refers to, respectively, as Princeton, other American cities, New Haven, and Baltimore. The narrator has personified them so as to reveal their physiological and psychological behaviour to her readers, especially, young Africans who want to emigrate to the US, because they consider that only America is the best place to live in. In addition to the three metafunctions, circumstances of location, manner and cause suggest that the narrator is first and foremost interested in giving detailed information related to racial issues from diverse angles.

In modelling communication, speakers adjust their language according to whom they speak to, what type of exchange that is underway and what their attitudes are (Watttles \& Radié-Bojanié, 2007, p. 52). Language choices that come from this variable of human interaction belong to the category of tenor and this is influenced or oriented by Mood (Halliday et al. 1964, pp. 90-92). The study of Mood patterns in the second excerpt from Americanah confirms the dominant existence of the declarative mood, followed by the interrogative and only one case of the imperative Mood. The exaggerate rate of the declarative mood clauses in the excerpt means that the text is made to inform readers about the characters' - Aunty Uju, Ifemelu, Bartholomew, and Dike -experience: their relationships and attitudes. They are conscious beings playing demander and giver roles. In the excerpt, apart from Aunty Uju who is involved in two questions in ( 2 and 3$)$, all the remaining questions have been put by Ifemelu who is demanding information regarding the origin, the profession and the status of the man who is about to visit her aunty. Aunty Uju, a giver of information, promptly provides answers for these questions. It can be understood from the foregoing that there is a frequent contact between Aunty Uju and Ifemelu, and they can see themselves as equal in power, in the communicative process because all of them can give or demand information alternatively.

From all these, readers are informed about the characters' experience as emigrants in the US where their skin colour and their English language, tinged with Nigerian culture, make them be considered as "others". Consequently, they feel relaxed when they are home or with people from their home country. This is the case of Bartholomew, a divorced and young accountant, who has paid a friendship visit to Aunty Uju in order to settle down again. The repetitive occurrence of declarative mood clauses and that of personal pronouns, used anaphorically to refer backward to characters, to provide information, clearly indicates that the tenor in/of this text is an informal one.The instance of the imperative mood found in 23 where Aunty Uju is "urgently" commanding Dike, her son, to behave well, as Bartholomew comes in, means that she has authoritative position and power over her son Dike.This single case also shows that Aunty Uju wants Dike to really keep quiet and be obedient towards her guest. It also suggests that she wants to show Bartholomew that she is an emancipated woman who deserves respect and deference.

Thematic analysis has been carried out at the level of clause. The investigation of Theme patterns in the excerpt from the novel under study, Americanah, reveals the presence of textual, interpersonal and topical Themes in the identified clauses. It is obviously noticed that topical Themes are predominant in the excerpt. This predominance suggests that, in all the clauses from the excerpt, there is at least a constituent in each clause to which we can attach a transitivity role such as Actor, Behaver, Senser or Circumstance. Such a situation indicates that the excerpt is reveals experiences (meanings about reality) shared by the participants (peacocks, Ifemelu and Obinze) in the extract and in the novel, to a larger extent.

Other Theme patterns studied in the third excerpt are textual ones. These are elements which, occurring in first position, do not express any interpersonal or experiential meaning but are doing important cohesive work in relating the clauses to their situational context in the excerpt (Eggins, 1994, p. 281). The fourteen (29) cases identified belong only to the category of conjunctive adjuncts which are, in other words, coordinators or subordinators or some other elements which serve to link clauses or clause complexes together, on the one hand, and express the relationship with what has been said earlier or so far, on the other. They enable participants/narrators to link clauses together so as to make sentences cohesively and coherently related. Interpersonal Themes are very low, i.e., $1 \%$, in the third excerpt. It indicates that the text is less concerned with an authoritarian tenor; the latter has been expressed in (5) through the comment adjunct "Perhaps". The above case reveals the lack of collaboration, absence of dialogue and exchange among the participants, Peacocks, Ifemelu and Obinze, in the excerpt because Ifemelu, as a new returnee from America, is only thinking about her fist love, Obinze, but in a sense of loss. Also, the participants express not only their personal opinions about precise matters but also their attitude and judgement through the use of this linguistic element in their conversation.

As regards the socio-cultural context of the production of the literary work, one can say that the entire story in Americanah crosses three continents- Africa, Europe, and America- and numerous lives. In the light of this inter-continental context of the novel, Chimamanda can be considered a citizen of the world, -but she refuses to be 
considered as such (Azodo, 2008). To show her standpoint, Austin (2014) quotes one of her answers in an interview: "I don't think of myself as anything like a global citizen or anything of the sort. I am just a Nigerian who's comfortable in other places". That may be the reason why Adichie has portrayed, in Americanah, characters leaving Nigeria not because they are underfed or because they have no other choice. They can simply be referred to as 'middle class refugees', determined to flee their home country as they can and escape from the menacing situation in a Nigeria under military dictatorship.

The award-winning Nigerian author, Chimamanda Ngozi Adichie is, thereby, addressing the question of immigration in her latest novel, Americanah. Seeing from the academic itinerary of the author, it can be inferred that she is, covertly, informing her readers about her own experience of leaving Nigeria and going to live in the US where the skin colour has become a major issue. Americanah, can, therefore, be considered as an articulate and outspoken artefact that pinpoints the many layers and implications of race, racism, love and cultural identity that African emigrants face in their daily lives. Actually, the key issue the author is depicting, through the lives of her characters, has to do with the concepts of race and racism through the lives of young African characters, Obinze and Ifemelu: university-educated Nigerians, who have emigrated to Europe and America where the context of racism matters more than in their home country Nigeria, in particular, and in Africa, in general. In fact, Chimamanda Ngozi Adichie has started with a classic tale of these young lovers, i.e., Ifemelu and Obinze, in Nigeria as the driving narrative of the whole novel. From the moment when their country is under military dictatorship, they leave, as many people are doing, to depart for America to study, in the case of Ifemelu, and for London, in the case of Obinze. Such a starting point of the novel makes readers reach the last pages of the novel without realizing that the novel is even about racial issues since it starts and ends as a love story. But this is a love story that travels, migrates, sees and learns many things from Ifemelu's point of view. We can conclude that Chimamanda Ngozi Adichie has used such a subtle writing strategy to covertly write about race so that only those who read between the lines can realize it is about racial prejudice, cultural identity and love at the same time.

\section{Conclusion}

This paper has surveyed the language of Americanah, a novel written by Chimamanda Ngozi Adichie, through the projector light of Systemic Functional Linguistics (SFL). It has aimed at investigating the different textual properties likely to sustain the message unfold in the novel. To arrive at a thorough understanding of these contexts, we have resorted to the analysis of lexico-grammatical features in three excerpts from the novel. The study of the socio-cultural environment of the production of the novel corroborates with the language that has been used to raise African youth generation's consciousness as far as the questions of immigration, love, race and identity in the context of today's globalised world are concerned. From the above analyses, we notice that the systemic functional approach has helped to unravel the writer's perception of the world-view, the social relationships language has played in the selected texts, and the way these texts are organised to convey the message of awareness. From the foregoing, it can be understood that the selected texts have fulfilled the research theoretical expectations and helped to better understand the language Chimamanda Ngozi Adichie has used in Americanah. These different analyses have led the researchers to say that Chimamanda Ngozi Adichie, as all language users, has predicted the meanings that are likely to be exchanged and the language that is likely to be used when she writes Americanah.

\section{References}

Adichie, C.N. (2013). Americanah. Ibadan: Farafina

Austin, P. (2014). "Becoming Americanah in Chimamanda Ngozi Adichie's novel on travelling, love and...yes, hair". A View From Elsewhere, Palacky University, Olomouc, Czech Republic, 15-16.

Azodo, A. U. (2008). "Interview With Chimamanda Ngozi Adichie: Creative Writing And Literary Activism", Retrieved from http://www.l3.ulg.ac.be/adichie/

Berger, P.L. \& Luckmann, T. (1976). The social construction of reality. Harmondsworth: Penguin.

Eggins, S. (1994). An Introduction to Systemic Functional Linguistics. London: Pinter Publisher.

Eggings, S. (2004). An Introduction to Systemic Functional Linguistics. London: Continuum.

Fowler, R. (1996). Linguistic criticism. (2nd ed.). London: Oxford University Press.

Halliday, M.A.K. \& Matthiessen, C.M.I.M. (2004). An Introduction to Functional Grammar. (2 ${ }^{\text {nd }}$ ed.). London: Edward Arnold.

Halliday, M.A.K. (1994). An Introduction to Functional Grammar. ( $2^{\text {nd }}$ ed.) London: Edward Arnold. 
Halliday, M.A.K. (1985a). An Introduction to Functional Grammar. London: Edward Arnold.

Halliday, M.A.K. (1978). Language as Social Semiotic: The Social Interpretation of Language and Meaning. London: Edward Arnold.

Halliday, M.A.K. \& Hasan, R. (1976). Cohesion in English. London: Longman. London and New York: Oxford University Press.

Halliday, M.A.K. et al. (1964). The Linguistic Sciences and Language Teaching. London: Longmans Green and Co Ltd

Koutchadé, I. S. (2015a). Thematic Structure and Foregrounding in Selected Extracts from Adetunji Ogundimu's A Silly Season. International Journal of English and Literature (IJEL), 5(4), 43-54.

Koutchadé, I. S. (2015b). Discourse Analysis of General Muhammadu Buhari's Official Acceptance Speech: A Systemic Functional Perspective. International Journal of English Linguistics, 5(5), 24-36. http://dx.doi.org/10.5539/ijel.v5n5p24.

Koutchadé, I. S. \& Mehouénou, S. (2016). Male-female Characters' Tenor of Discourse in Akachi Ezeigbo's The Last of the Strong Ones. International Journal of Linguistics, 8(3), 167-182. http://dx.doi.org/10.5296/ijl.v8i3.9662

Kyrala, C. (2010). Systemic Linguistic Analysis of Samples from Economic Speeches by Barack Obama and John McCain. Journal of Language and Politics, (9)1, 74-95. http://dx.doi.org/10.1075/jlp.9.1.04kyr

Lyons, J. (Ed). (1970). New horizons in linguistics.Harmondsworh: Penguin.

Martin, J. \& Rose, D. (2003).Working with Discourse: Meaning Beyond the Clause. London: Continuum.

Matthiessen, C.M.I.M. (1995). Lexicographical Cartography: English Systems. Tokyo: International Language Sciences Publishers.

Wattles, I. \& Radié-Bojanié, B. (2007). The Analysis of an Online Debate- The Systemic Functional Grammar Approach. Linguistics and Literature, 5(1), 47-58. 